\title{
Ensuring the Preparedness and Development of an Emergency Response Plan in the Fight Against the COVID-19 Outbreak in Libya
}

\author{
Saurabh Shrivastava, ${ }^{1}$ (1) Prateek Shrivastava ${ }^{2}$ \\ 'Department of Community Medicine, Member of the Medical Education Unit and Institute \\ Research Council, Shri Sathya Sai Medical College \& Research Institute, Sri Balaji Vidyapeeth - \\ Deemed to be University, Ammapettai, Nellikuppam, Chengalpet District, Tamil Nadu, India \\ ${ }^{2}$ Department of Community Medicine, Shri Sathya Sai Medical College \& Research Institute, Sri \\ Balaji Vidyapeeth - Deemed to be University, Ammapettai, Nellikuppam, Chengalpet District, \\ Tamil Nadu, India
}

\section{ABSTRACT}

The Corona Virus Disease-2019 (COVID-19) outbreak has been declared a public health emergency with international concern and a pandemic. Libya is one of the countries in the Eastern Mediterranean region, which has reported 65 cases and 3 deaths to date. The situation in Libya is getting more complicated due to the ongoing conflict that started in February 2015 to take the administrative control in the country. Amid all these alarming developments regarding to the global COVID-19 outbreak and the ongoing skirmishes in Libya, the United Nations has requested a ceasefire from all parties involved in the conflict. The political leaders should aim for strengthening case detection, isolation, infection prevention, treatment, surveillance, risk communication and contact monitoring activities. As a result, the consequences of a COVID-19 outbreak in Libya could be catastrophic unless an urgent and accelerated response to the infection is given. All conflicting parties in the country must agree to ceasefire and focus their interests and resources on preparedness and emergency response plan activities at this time.

Keywords: COVID-19, Libya, World Health Organization

\section{INTRODUCTION}

The Corona Virus Disease-2019 (COVID-19) outbreak, which has been declared a public health emergency of international significance and a pandemic, has sparked a worldwide fear and raised serious objections about the level of preparation and the emergency response plan. ${ }^{[1,2]}$ The latest available estimates show that a total of 4618821 cases have been reported worldwide, of which 311847 have lost their lives due to this novel infection. ${ }^{[1]}$ The global case mortality rate of the infection is $6.75 \%$, compared to $8.8 \%$ and $2.9 \%$ in the European region and Eastern Mediterranean region..$^{[1]}$ It is important to note that no individual or, national population group is immune to this infection and therefore a concerted response is needed to effectively control the public health emergency. ${ }^{[1,2]}$

\section{COVID-19 in the Eastern Mediterranean Region}

A total of 338560 cases and 9979 deaths have been reported in 21 countries affected by the outbreak in Eastern Mediterranean region with evidence of community transmission in four of these countries. ${ }^{[1]}$ It is important to note that as most of the countries in the region are de- 
veloping countries, they have several other public health priorities and a poor health care delivery system. ${ }^{[2,3]}$ At the same time, some of these countries are already experiencing emergency humanitarian situations due to the current conflicts, and it seems difficult for these countries to control the infection, given that even the developed countries having advanced health infrastructure find it challenging to control the disease. ${ }^{[3]}$

\section{COVID-19 in Libya}

Libya is one of the countries in the Eastern Mediterranean region, which has reported 65 cases and 3 deaths so far. [1] However, Algeria (7019 cases), Egypt (12229 cases) and Sudan (2591 cases) surrounding Libya reported cases within their geographic borders. ${ }^{[1]}$ The situation in Libya is further complicated due to the ongoing conflict that began in February 2015 to gain the administrative control in the country. ${ }^{[3]}$ Moreover, the political instability and insecurity caused by these conflicts have already jeopardized the health and welfare sector of the country, and thousands of people have either lost their lives or become refugees. ${ }^{[3,4]}$ According to estimates from the country 823000 people need humanitarian aid access to health care service, and are deprived of basic human rights or welfare services. ${ }^{[3]}$

\section{Preparedness and Emergency Response}

Amid all the alarming developments related to the global COVID-19 outbreak and the ongoing conflict in Libya, the United Nations has requested a ceasefire from all parties involved in the conflict. ${ }^{[4]}$ What is needed now; the use of public health authorities in the preparedness and the formulation of a response action plan in the country. ${ }^{[4,5]}$ It is also important to point out that the health sector cannot respond to this pandemic alone and we need an integrated response from all relevant sectors (i.e. education, trade, travel, etc.). ${ }^{[2,4,5]}$

The political leaders should aim to strengthen case detection, isolation, infection prevention, treatment, surveillance, risk communication and contact monitoring activities. ${ }^{[5]}$ Specific interventions should be made to ensure that only reliable information is passed on to the general population through reliable sources and all kinds of myths and misconceptions should be clarified as a priority. ${ }^{[5]}$ At the same time, interventions should be made among local people to raise the awareness about the disease, its mode of transmission and methods for the preventing the dis- ease (i.e. avoiding close contact with the confirmed or suspicious cases, social gatherings and delaying unnecessary travel).$^{[4,5]}$ Moreover, awareness activities should be carried out to educate people about the importance of hand hygiene, respiratory hygiene, use of personal protective equipment, periodic cleaning \& disinfection of the contaminated surfaces, and safe disposal of the contaminated medical masks or tissues. ${ }^{[4,5]}$ All these interventions will play an important role in improving the mental wellbeing of the citizens and also calm down the fear and anxiety attributed to the disease due to its new nature.

\section{CONCLUSION}

As a result, the consequences of a COVID-19 outbreak in Libya could be disastrous, if we don't provide an immediate and accelerated response to the infection. It is time for all the conflicting parties in the country to reach a ceasefire and focus their interests and resources on preparedness and emergency response plan activities.

\section{Disclosures}

Peer-review: Externally peer-reviewed.

Conflict of Interest: None declared.

Authorship contributions: Concept - S.R.S.; Design - S.R.S., P.S.S.; Supervision - S.R.S., P.S.S.; Analysis and/or interpretation S.R.S., P.S.S.; Literature search - P.S.S.; Writing - S.R.S.; Critical Review - S.R.S., P.S.S.

\section{REFERENCES}

1. WHO. Coronavirus disease 2019 (COVID-19) Situation Report - 119; 2020. Available at: https://www.who.int/docs/ default-source/coronaviruse/situation-reports/20200518-covid-19-sitrep-119.pdf?sfvrsn=4bd9de25_4. Accessed May 19, 2020.

2. Lee A. Wuhan novel coronavirus (COVID-19): why global control is challenging? Public Health 2020;179:A1-A2. [CrossRef]

3. WHO. Libya humanitarian response plan 2019. Geneva: WHO press; 2018. p. 1-18.

4. WHO. UNSMIL appeals for ceasefire to strengthen COVID-19 response; 2020. Available at: http://www.emro.who.int/lby/ libya-news/unsmil-appeals-for-ceasefire-to-strengthen-covid-response.html. Accessed May 19, 2020.

5. WHO. 2019 Novel Coronavirus (2019-nCoV): Strategic preparedness and response plan. Geneva: WHO press; 2020. p. 1-20. 